\title{
A UNIÃO EUROPEIA: UM ATOR INTERNACIONAL FORMADO POR UMA CONSTELAÇÃO DE ESTADOS
}

\author{
THE EUROPEAN UNION: AN INTERNATIONAL ACTOR FORMED BY A \\ CONSTELLATION OF STATES
}

\author{
Augusto Jaeger Junior ${ }^{1}$ \\ Mariana Sebalhos Jorge ${ }^{2}$
}

Submissão: 07/10/2020 / Aceito:06/03/2021 / Publicado: 18/03/2021.

\begin{abstract}
Resumo
O presente artigo pretende analisar a União Europeia enquanto ator internacional. Em um primeiro momento, serão analisadas as teorias da integração regional, como o federalismo, o funcionalismo, o neofuncionalismo, a interdependência, o intergovernamentalismo e o neoinstitucionalismo. Em um segundo momento, será analisada a realidade da União Europeia, observando a evolução histórica desta integração regional e a sua presença como ator internacional. É possível pensar em um bloco regional como um ator internacional único, ainda que formado por uma constelação de Estados? A União Europeia assumiu, nos últimos anos, uma posição de destaque na sociedade internacional que justifica e contextualiza o presente debate.
\end{abstract}

Palavras-chave: Integração regional. União Europeia. Ator internacional. Estadosmembros.

\begin{abstract}
This article aims to analyze the European Union as an international actor. At first, regional integration theories will be analyzed, such as federalism, functionalism, neofunctionalism, interdependence, intergovernmentalism and neoinstitutionalism. In a second moment, the reality of the European Union will be analyzed, observing the historical evolution of this regional integration and its presence as an international actor. Is it possible to think of a

\footnotetext{
${ }^{1}$ Professor Permanente do Programa de Pós-Graduação em Direito da UFRGS, em Porto Alegre. Professor Associado da Faculdade de Direito da UFRGS. Líder do Grupo de Pesquisa "Direito Internacional da Concorrência" (UFRGS/CNPq). Bolsista de Produtividade em Pesquisa do CNPq. Pós-doutor pela Alexander von Humboldt-Stiftung na Universidade de Heidelberg, Alemanha. Doutor em Direito Comunitário pela UFRGS. Mestre em Direito Internacional pela UFSC, sob a orientação da Profa. Dra. Odete Maria de Oliveira. Autor e organizador de livros sobre a temática da União Europeia, tais como Europeização do Direito Internacional Privado: Caráter Universal da Lei Aplicável e outros Contrastes com o Ordenamento Jurídico Brasileiro. Curitiba: Juruá Editora, 2012. 672 p. e Europeização da parte geral do direito internacional privado: estudos sobre uma codificação do direito internacional privado na União Europeia através de um Regulamento Roma Zero. Porto Alegre: Editora RJR, 2016. 584 p., entre outros. E-mail: augusto.jaeger@ufrgs.br

${ }^{2}$ Doutora em Direito Internacional pela Universidade de São Paulo (USP). Mestre em Direito Internacional pela Universidade Federal do Rio Grande do Sul (UFRGS). Bacharel em Relações Internacionais pela Universidade Federal de Santa Maria (UFSM). Bacharel em Direito pelo Centro Universitário Franciscano (UNIFRA). Membro do Grupo de Pesquisa "Direito Internacional da Concorrência" (UFRGS/CNPq). Membro do "Grupo de Pesquisa sobre a Pluralidade das Fontes no Direito Internacional Privado e o Brasil" (USP). Email: msebalhos@gmail.com
} 
regional bloc as a single international actor, even though formed by a constellation of states? The European Union has, in recent years, assumed a prominent position in international society that justifies and updates this debate.

Keywords: Regional integration. European Union. International actor. Member States.

\section{INTRODUÇÃO}

Foi com alegria que observamos o surgimento dessa publicação da Unochapecó e identificamos a oportunidade de fazer mais uma justa e merecida homenagem à Professora Titular de Relações Internacionais da Universidade Federal de Santa Catarina, Doutora Odete Maria de Oliveira, mestra de todos nós, em Chapecó, na cidade em que ela lecionou ultimamente, após a sua aposentadoria na Federal.

Augusto Jaeger Junior a conheceu pessoalmente no segundo semestre do ano de 1997. Naquela época, o coautor desse artigo era aluno do Curso de Mestrado da UFSC e telefonou para ela para convidá-la e ver da sua disponibilidade para ser sua orientadora em uma dissertação que viria a levar o título de Mercosul e a livre circulação de pessoas. Do outro lado da linha atendeu-lhe uma voz simpática, amável, características da pessoa da professora Odete que, dentre tantas outras de caráter pessoal, se sobressaíram em suas aulas, posteriormente.

O seu apreço pelo contato estabelecido e contentamento foi tão grande que naturalmente convenceu dois outros colegas do curso, os professores Florisbal de Souza Del'Olmo e Gilberto Kerber, a fazerem o mesmo.

A partir de então, as orientações que recebeu da professora Odete foram verdadeiras lições de vida. A amistosa relação estabelecida e a transmissão frequente de conhecimentos o conduziram a uma defesa segura da sua dissertação de mestrado em 1999.

Mas Augusto Jaeger Junior não tem como deixar de lembrar também de conjuntas proezas não acadêmicas daquela época. Por exemplo, da foto do entardecer na Praia do Campeche, que virou a maravilhosa capa do seu primeiro livro. Das fotos que tiraram nos cemitérios jesuítas de São João Batista e de São Miguel das Missões, no Rio Grande do Sul. E das que tiraram naquele rio de coloração alaranjada, na Serra do Rio do Rastro, em Santa Catarina, que viraram a capa do seu segundo livro. E como não se recordar dos almoços no Arante, em Florianópolis. Ótimos, claro, mas nada comparável à carne de panela feita com amor pela Dona Erna, degustada na varanda da casa de Serendipity. E como deixar de lembrar da peregrinação nas ruazinhas de Assunção, atrás de uma lente nova, potente, para a máquina 
fotográfica que a cada dia fazia maravilhas de fotografias, quando estiveram presenciando a defesa de doutorado do Professor Doutor Luiz Otávio Pimentel, quem também teve o coautor o prazer de conhecer através da mestra catarinense e de ser colega de universidade, quando lecionou em Chapecó. E das orações na santinha do Santuário de Schoenstatt, em Santo Ângelo. E da sopa de aspargos novos, em Chapecó, sede da universidade à qual a mestra se dedicou nos últimos anos. E dos encontros nos Encontros de Direito da América do Sul pela América do Sul afora. Enfim, dedicamos esse singelo artigo científico às boas lembranças de momentos em conjunto com a professora Odete!

Academicamente, a professora Odete segue nos brindando a cada momento com novas ideias, obras e oportunidades. Não foi uma única vez que dela recebemos o chamado para publicar artigos em seus livros organizados. As suas palavras doces e acalentadoras são aplicadas a qualquer dificuldade. Juntamente com a profundidade de seu conhecimento, havia a bondade e a generosidade constantes. Por tudo o que dela recebeu, hoje o coautor Augusto Jaeger Junior a homenageia humildemente com este artigo escrito em conjunto com uma pesquisadora com origem nas Relações Internacionais, graduada pela Universidade Federal de Santa Maria (UFSM), que é a Doutora Mariana Sebalhos Jorge. O tema não poderia ser outro, que não a União Europeia, aqui analisada a partir da sua presença enquanto ator no cenário internacional.

Isto posto, tem-se que inúmeros são os fatores que interferem nas decisões de Estados soberanos - por anos, os únicos, depois os principais, atores do sistema internacional. Com a globalização, a integração regional se intensifica. Nas palavras de Odete Maria de Oliveira (2002, p. 29), “a superação de um panorama relacional de soberania, até então exclusivo do Estado nacional, não se positiva através de puro ato de reflexão racionalizada sobre as inovações da sociedade internacional globalizada", mas, sim, “[...] como expressão compulsiva de crises e necessidades explícitas de uma série de Estados". A integração regional na Europa, por exemplo, “emerge no cenário internacional como resultado de acordos políticos entre países vizinhos ou geograficamente próximos, objetivando vantagens de cooperação decorrentes desse processo" (OLIVEIRA, 2002, p. 34), como se pode ler na obra que resultou do pós-doutorado da autora na Universidade Complutense de Madrid.

Assim, o presente artigo pretende questionar a possibilidade de um bloco regional como a União Europeia ser considerado um ator internacional único, ainda que formado por uma constelação de Estados. A fim de debater essas questões, o texto será dividido em duas 
partes. A primeira parte irá abordar as diferentes teorias da integração, como o federalismo, o funcionalismo, o neofuncionalismo, a interdependência, o intergovernamentalismo e o neoinstitucionalismo. A segunda parte focará na realidade específica da União Europeia, observando o desenvolvimento da integração regional no bloco europeu e a sua situação atual como ator do sistema internacional.

É possível que a União Europeia atue no sistema internacional com uma identidade própria, defendendo interesses e posturas diplomáticas próprias do bloco econômico? Ou a sua atuação no sistema internacional será exclusivamente baseada nos interesses dos seus Estados-Membros, sendo incapaz de adquirir certa autonomia? As respostas a essas perguntas deverão considerar o cenário atual existente no bloco europeu, retratando as consequências do Brexit, a saída do Reino Unido da União Europeia.

\section{AS TEORIAS DE INTEGRAÇÃO E OS ATORES INTERNACIONAIS}

\section{As teorias da integração: o federalismo, o funcionalismo e o neofuncionalismo}

Na medida em que o processo de integração entre os Estados avançava, iam sendo aprimoradas as tentativas de construção de uma teoria geral da integração. Essas tentativas "ocupavam-se, principalmente, com conceitos direcionados a três questões fundamentais: o que é integração, qual o seu resultado final e quais as causas que estimulam o seu processo" (OLIVEIRA, 2002, p. 46). Destacam-se, assim, as principais teorias da integração existentes, como o federalismo, o funcionalismo e o neofuncionalismo.

O federalismo aborda a importância da criação de instituições que passariam a ter parte da soberania dos Estados. Estes estariam dispostos a conceder parte de sua soberania a uma instituição superior: "os Estados concordariam em abandonar os seus armamentos nacionais e aceitariam um certo nível de autoridade central" (NYE, 2002, p. 262). Conforme Odete Maria de Oliveira, o pensamento federalista se concentra em estruturar a então Comunidade Europeia com as características próprias do modelo federal. O federalismo “pretende reconhecer nos órgãos estabelecidos pelos Tratados constitutivos similitudes com a organização constitucional do Estado federal", invocando "[...] a supremacia do direito comunitário sobre os direitos dos Estados-Membros e de certas disposições comunitárias auto aplicadas e obrigatórias no ordenamento jurídico dos Estados-Membros” (OLIVEIRA, 2002, p. 47-48). 
Já a teoria do funcionalismo surgiu para suprir as lacunas do federalismo. Nas palavras de Odete Maria de Oliveira (2002, p. 49), "como teoria da integração, o funcionalismo apresenta-se em forma de réplica ao federalismo". Defende também a existência de instituições, porém não transfere a estas a soberania estatal como o federalismo: certas responsabilidades estatais deveriam ser repassadas a instituições que se responsabilizariam por tais atividades. Nesse sentido, “o funcionalismo sugeria que a cooperação econômica e social poderia gerar comunidades que atravessassem fronteiras nacionais", de modo que "[...] a soberania tornar-se-ia então menos relevante e, apesar da estrutura formal do estado continuar a existir, o seu conteúdo hostil seria drenado" (NYE, 2002, p. 262).

A teoria do funcionalismo adere ao princípio da paz universal entre as nações, mas “diverge da tese de que a criação de um governo supranacional seria o meio de atingir a concretização pregada por tal princípio" (OLIVEIRA, 2002, p. 49).

Já a teoria do neofuncionalismo obteve grande importância com o processo de integração na Europa. Para Ernst Haas (1964, p. 710), um dos fundadores dessa teoria, a “integração significa o processo de transferência das expectativas excludentes de benefícios do Estado-nação para alguma entidade maior”. Karl Deutsch (1982, p. 268) destaca quatro condições básicas para a integração: “importância recíproca das unidades; compatibilidade entre valores e certas vantagens conjuntas reais; influência mútua; e certo grau de identidade comum generalizada ou lealdade comum generalizada".

O neofuncionalismo contribuiu na identificação da causa do processo de integração, afirmando que "existe um mecanismo que faz avançar a integração, o princípio do spill over ou do transbordamento" (OLIVEIRA, 2002, p. 51). Para Odete Maria de Oliveira (2002, p. 51), o processo de integração por etapas escalonadas e em diferentes saltos qualitativos "constitui a lógica expansiva da integração por setores".

\section{A teoria da integração a partir da interdependência, do intergovernamentalismo e do neoinstitucionalismo}

Com as ineficiências das teorias da integração existentes, percebem-se tentativas de associar a integração com as teorias da interdependência, do intergovernamentalismo e do neoinstitucionalismo. Para Odete Maria de Oliveira (2002, p. 53), “o fracasso das teorias específicas sobre a integração conduziu seus estudos aos paradigmas e esquemas teóricos das 
relações internacionais, as relações de poder entre os Estados do ponto de vista da interdependência e do inter-governamentalismo".

A associação da integração à teoria da interdependência ocorre no momento em que se percebe que o seu conceito "não era mais apropriado a descrever os processos e as consequências políticas registradas dentro do âmbito regional da União Europeia" (OLIVEIRA, 2002, p. 53). Assim, a integração passaria a ser entendida "como processo institucionalizado, desenhado pelos governos para adaptar às condições de interdependência, porém, sem considerar a integração progressiva de políticas como uma consequência necessária" (OLIVEIRA, 2002, p. 53).

Ao aproximar a teoria da integração com o intergovernamentalismo, observa-se o argumento de que "os membros da União Europeia estão empenhados em processo de formação de nova entidade, uma entidade supranacional, que irá substituir o velho Estado nação, em virtude de certas políticas de reciprocidade mútua ou de jogo de soma zero", ou seja, "[...] o que um Estado perde em soberania ganha em outra atividade" (OLIVEIRA, 2002, p. 54).

A aproximação da teoria da integração ao intergovernamentalismo baseia-se em três princípios. O primeiro seria a premissa de que os governos nacionais são os atores principais, enquanto o bloco regional, tal como a União Europeia, é considerado "um campo para a continuação das políticas domésticas por outros meios" (OLIVEIRA, 2002, p. 55). O segundo princípio seria de que as negociações são feitas por um denominador comum mínimo, e o terceiro corresponde a uma proteção das soberanias nacionais dos EstadosMembros a fim de evitar uma outorga sem limites às instituições comunitárias (OLIVEIRA, 2002, p. 55).

Conforme Odete Maria de Oliveira (2002, p. 55), este paradigma tem vantagem ao explicar um resultado formal concreto como o Tratado do Ato Único Europeu, surgido na metade da década de 80 , pela "convergência conjuntural de interesses entre os Estados maiores (convergência de preferência)", ao mesmo tempo em que apresenta dificuldade em considerar que "tanto as instituições como as políticas comunitárias sempre influenciam o processo".

No neoinstitucionalismo, no entanto, o comportamento dos atores não é elemento central como no intergovernamentalismo, "mas está mediatizado pelas instituições onde se emoldura, tendo em vista que a instituição é algo mais que um simples órgão formal" 
(OLIVEIRA, 2002, p. 56). Duas características institucionais do processo de integração europeia permeiam o entendimento do neoinstitucionalismo. A primeira é que os governos participam diretamente junto às decisões centrais, e a segunda é que existe um requisito de fato de decisões unânimes.

O direito da integração corresponde à união de Estados em busca de cooperação econômica e política, através de normas comuns. O direito da integração, em sua fase mais consolidada, prevê a criação de uma entidade supranacional que não representará os interesses de um único Estado em si. O que se percebe, atualmente, é que a integração regional foi uma resposta aos efeitos da globalização, e a complexidade do assunto dificulta a ascensão de uma teoria geral. Os movimentos da globalização e da regionalização correspondem a fenômenos "característicos da sociedade internacional contemporânea, refletindo o impasse estatal frente à impossibilidade de realizar adequadamente suas funções, a menos que se integre a outros Estados mediante mecanismos de organização de interesse comum e estrutura diferenciada" (OLIVEIRA, 2002, p. 56).

A União Europeia é, atualmente, um exemplo de uma integração regional avançada, que adquiriu uma identidade própria e que possui instituições supranacionais já consolidadas. É possível afirmar que já existe uma codificação unional com direitos e deveres que transcendem a esfera nacional de cada Estado-Membro. Afirma-se que "a União Europeia se materializa através de um conjunto complexo de instituições e procedimentos, cujo fundamento político e social transcende os âmbitos internos e aos interesses individualizados dos Estados-Membros” (OLIVEIRA, 2002, p. 128). Para além, já teria uma constituição (MICHAELS, 2008, p. 1607-1644). Vale constar, nesse aspecto, a (quase) constitucionalização de determinados ramos do direito, como o direito internacional privado da União Europeia. Como sabido, a questão é singular, uma vez que a União Europeia não tem uma constituição real. O Tratado para uma Constituição para a Europa resultou inexitoso após os referenda na França e na Holanda (JAEGER JUNIOR; HERZOG, 2007, p. 93-120). Mas, em resposta, a União Europeia aprovou, de forma mais modesta, o Tratado de Lisboa, que pode ser apresentado como um tratado reformador (JAEGER JUNIOR, 2010). Para Ralf Michaels (2008, p. 1607-1644), funcionalmente, o Tratado opera como uma constituição, e o seu impacto nas regras sobre o conflito de leis é, do ponto de vista estrutural, similar àquele impacto das constituições das outras nações nas regras domésticas sobre o conflito de leis. Enfim, seria possível concluir que a União Europeia tem uma constituição, se não formal, ao 
menos material, e o direito internacional privado teria sido constitucionalizado, como prega Michaels.

\section{A União EUROPEIA}

\section{A União Europeia: breve evolução histórica}

O início da integração regional no continente europeu foi marcado pela assinatura do Tratado da Comunidade Econômica Europeia para o Carvão e o Aço (TCECA), baseado no plano Schuman, e assinado pela Alemanha, França, Itália e pelos três Estados da União Econômica do Benelux (Bélgica, Luxemburgo e Holanda). O TCECA entrou em vigor em julho de 1952, com o objetivo de, no âmbito dos recursos de carvão e aço, promover a criação de um mercado comum sem fronteiras - representava, na época, um bloco econômico de 198 milhões de pessoas.

No âmbito da integração política e econômica, é possível ser dito que a experiência obtida pela Comunidade Econômica Europeia para o Carvão e o Aço influenciou o surgimento dos tratados seguintes: o Tratado da Comunidade Econômica Europeia para a Energia Atômica (TCEEA) e o Tratado da Comunidade Econômica Europeia (TCEE). O momento da assinatura dos tratados representou "o desejo de um bem-estar econômico, segurança e um papel construtivo da Europa na política mundial" (JAEGER JUNIOR, 2010, p. 50). Assim, em março de 1957, os dois novos tratados foram assinados e as duas novas comunidades foram fundadas: duas entidades supranacionais, diferentes das organizações internacionais tradicionais, pois representavam mais que uma simples cooperação interestatal.

A Comunidade Econômica Europeia foi a que alcançou um maior significado, uma vez que não estava limitada a um determinado setor econômico, já que abrangia todos os ramos da economia entre os Estados-Membros e as suas relações com Estados terceiros. Por essa razão, é considerado um acordo básico no qual são estatuídos apenas princípios fundamentais. Os anos que se seguiram representaram o alargamento das comunidades existentes, com a incorporação de novos Estados-Membros, ampliando a integração.

Em 1992, foi assinado o Tratado da União Europeia (TUE), também conhecido como Tratado de Maastricht. A Comunidade Econômica Europeia (CEE) passou a chamar-se apenas Comunidade Europeia (CE), ultrapassando os objetivos meramente econômicos. Foram definidas regras para uma união econômica e monetária - pedra fundamental do TUE 
-, e para uma “cidadania da União, com a participação ativa e passiva dos cidadãos em eleições comunitárias e municipais" (JAEGER JUNIOR, 2010, p. 54; BRU, 1994). O advento do TUE em Maastricht trouxe uma série de consequências, sendo que a primeira foi a coexistência da Comunidade (MOLINA DEL POZO, 2015, p. 159)³.

Outra importante modificação ocorreu em 2007, com a assinatura do Tratado de Lisboa: "entrou em vigor em 01.12.2009, vindo a promover profundas alterações no processo de integração e uma completa nova renumeração das disposições dos tratados existentes" (JAEGER JUNIOR, 2010, p. 58). Assim, o TUE teve as suas disposições renumeradas pelo Tratado de Lisboa. O mesmo ocorreu com o TCE, que, desde a entrada em vigor do novo documento, passou a chamar-se Tratado sobre o Funcionamento da União Europeia (TFUE). As Comunidades remanescentes foram fundidas na UE, que passou a ser a única instituição existente, possuindo personalidade jurídica.

Com o advento do Tratado de Lisboa, a busca pela identidade da União no âmbito internacional passou a ser um dos objetivos do bloco, por meio de uma política exterior e de segurança comum. Odete Maria de Oliveira (2009, p. 170) destaca, ainda, a criação de uma cidadania da União, a fim de proteger os direitos e os interesses daqueles que viviam no espaço comunitário.

A tendência à integração e à regionalização na sociedade contemporânea reflete "o impasse da fragilidade do Estado que, frente a impossibilidade de cumprir com suas funções estatais, integra-se a outros Estados, desenhando os mais diversificados modelos de integração, como, no caso, das Comunidades Europeias” (OLIVEIRA, 2002, p. 449).

\section{A União Europeia enquanto ator internacional}

Analisar a União Europeia enquanto ator internacional origina certos questionamentos (GEHRING; OBERTHUR; MUHLECK, 2010, p. 852): é possível que o bloco se torne um ator internacional por si só, capaz de agir separadamente de seus EstadosMembros, mesmo que dependa inteiramente de recursos derivados desses Estados e de suas sociedades?

\footnotetext{
${ }^{3}$ Tradução livre de: "El nacimiento del TUE en Maastricht trae una serie de consecuencias, la primera de ellas, la coexistencia de la Comunidad".
} 
Existe um consenso de que a União Europeia possui uma "presença internacional", visível em fóruns regionais e globais, e que é um ator internacional em algumas áreas, mas não em outras (GINSBERG, 1999, p. 432). Ainda assim, a importância da UE no meio internacional impulsiona a sua visão como um ator internacional. Para um rápido exemplo, cita-se a sua associação à Conferência de Haia para o Direito Internacional Privado. As vantagens de participar de um esforço mundial que teve sucesso não são comparáveis às estabelecidas dentro de sua própria fortaleza, relacionadas unicamente com os seus próprios interesses e se mostrando hostil aos interesses dos terceiros países. Com efeito, a União Europeia foi autorizada a candidatar-se para a Conferência de Haia de Direito Internacional Privado por uma decisão do Conselho, datada de 5 de novembro de 2006 (BORRAS, 2006, p. 1179-1189). O seu efetivo ingresso na organização carecia de uma alteração do estatuto para permitir que as organizações regionais de integração econômica pudessem se tornar membros da Conferência de Haia. Então a União Europeia pleiteou a alteração do Estatuto da Conferência de Haia de Direito Internacional Privado para permitir que as organizações regionais de integração econômica se tornassem membros da Conferência de Haia. A proposta foi aceita, e as modificações no estatuto entraram em vigor em $1^{\circ}$. de janeiro de 2007.

O comportamento da União Europeia ratifica a sua posição como ator internacional: “certas ações de política externa refletem uma marca europeia única de diplomacia, moldada por uma dinâmica interna de cooperação entre membros e instituições comuns ${ }^{4}$, (GINSBERG, 1999, p. 439). Nesse sentido, Karen Smith (2003, p. 104-105) afirma que a UE possui uma presença considerável nos assuntos internacionais: é o maior bloco comercial do mundo e as suas políticas internas afetam outros atores internacionais.

É preciso refletir, no entanto, que a capacidade de ação da União Europeia depende da liberdade concedida pelos Estados-Membros: a capacidade de ação será restringida e seu papel internacional será diminuído se os Estados-Membros se recusarem a permitir que a União Europeia assuma a responsabilidade pelas principais políticas e relações externas (GINSBERG, 1999, p. 447).

Evidentemente, os Estados-Membros da União Europeia concordam frequentemente com objetivos comuns e mobilizam recursos para alcançá-los. Isso porque existem incentivos

\footnotetext{
${ }^{4}$ Tradução livre de: "Certain EFP actions reflect a unique European brand of diplomacy and foreign policy molded by an internal dynamic of cooperation among members and common institutions".
} 
para a elaboração de políticas comuns, uma vez que os Estados-Membros reconhecem que terão uma força maior quando agirem como um bloco, juntos. Porém, os mecanismos e resultados da política externa da União Europeia "ainda refletem claramente a tensão entre os desejos de agir coletivamente nas relações internacionais e de manter prerrogativas nacionais na política externa ${ }^{5}$ " (SMITH, 2003, p. 105). Esse é um dos motivos apontados para o insucesso do Tratado para uma Constituição para a Europa.

Destaca-se que a União Europeia pode ser considerada "um novo tipo de ator internacional", uma vez que atrai países e não ameaça aqueles que estão fora do bloco. Ao passo em que os países europeus uniam-se, esperava-se o surgimento de uma coalizão oposta, a partir da teoria do equilíbrio de poder. No entanto, os países externos ao bloco buscam ingressar na União Europeia ou vincular-se a ela (SMITH, 2003, p. 110).

Conforme Ruxandra Laura Bosilca (2014, p. 23), por um lado, o papel externo da União Europeia excede o de qualquer outra organização internacional; por outro, a União carece de características de um Estado soberano, o que impede o desenvolvimento de uma estrutura capaz de suportar relações interestatais.

Percebe-se, nesse sentido, que a entrada em vigor do Tratado de Lisboa trouxe importantes inovações, visando fornecer consistência e visibilidade à ação externa da União Europeia. Ainda que estes objetivos tenham sido, em parte, alcançados, a construção de um serviço diplomático global da União Europeia é um "trabalho em andamento" com inúmeros desafios institucionais e jurídicos (BOSILCA, 2014, p. 31).

Para Karen Smith (2003, p. 108), a longo prazo, a União Europeia pode contribuir para a transformação do sistema internacional, reforçando elementos da sociedade internacional, como o direito internacional e a cooperação entre Estados. A disseminação do regionalismo, por exemplo, pode ser associada à existência da União Europeia e das suas políticas de incentivo à cooperação regional.

Desde 2016, no entanto, novas questões surgem envolvendo a União Europeia. Em 23 de junho, o Reino Unido votou um plebiscito a fim de determinar a sua saída ou permanência no bloco europeu: $52 \%$ dos votos decidiram pela saída, que foi notificada à UE em março de $2017^{6}$.

\footnotetext{
${ }^{5}$ Tradução livre de: "But the EU's foreign policy mechanisms and output still clearly reflect the tension between the desires to act collectively in international relations and to retain national prerogatives in foreign policy".

${ }^{6}$ Nas palavras de Michael Waibel (2018, p. 440): “Em 29 de março de 2017, o governo do Reino Unido acionou o artigo 50 do Tratado da União Europeia (TUE) sobre a retirada da União Europeia após um referendo realizado 
Conforme o artigo $50^{\circ}$ do Tratado de Lisboa, após essa notificação, o desmembramento devia ocorrer no prazo de dois anos. O movimento de saída do Reino Unido da União Europeia ficou conhecido como Brexit. A saída oficializou-se no dia 31 de janeiro de 2020, dando início ao período de transição. Para Ágnes Kertész, (2016, p. 93) "no momento em que foi redigido o Tratado de Lisboa e foi inserida uma disposição sobre a eventual saída de um Estado-Membro, ninguém realmente pensava que essa disposição seria aplicada e muito menos que seria tão cedo ${ }^{7 \%}$.

Os impactos da saída do Reino Unido da União Europeia geram, atualmente, mais questionamentos e dúvidas do que certezas ${ }^{8}$. Não há como saber se a saída do Reino Unido incentivará outros países a seguirem o mesmo caminho ou se ratificará a importância da integração para as economias nacionais (DIZ; JALES, 2019, p. 277-306). É imprevisível também compreender como essa saída afetará a União Europeia enquanto ator internacional: haverá um fortalecimento da identidade comunitária ou um enfraquecimento? Essas são apenas algumas questões que fomentam a incerteza que permeia esse momento político, econômico e social que atingirá a União Europeia nos próximos anos.

\section{CONSIDERAÇÕES FINAIS}

A União Europeia é, atualmente, a integração regional mais avançada no sistema internacional, não somente pelo número de Estados que a formam, mas também pelo perfil destes Estados. Odete Maria de Oliveira (2002, p. 34) destaca que "frente ao acelerado fenômeno da economia globalizada, os países cada vez se tornam mais dependentes, instáveis e desequilibrados, buscando junto à tentativa do paradigma alternativo de economias regionais, seus fortalecimentos".

em 23 de junho de 2016, no qual 51,89\% votaram pela saída do Reino Unido da União Europeia”. Tradução livre de: "On March 29, 2017, the U.K. Government triggered Article 50 of the Treaty on European Union (TEU) on withdrawal from the European Union following a referendum on June 23, 2016 in which 51.89 percent voted for the United Kingdom to leave the European Union".

${ }^{7}$ Tradução livre de: "When, at the time of drafting the Lisbon Treaty (and before that the EU Constitution), a provision on the eventual withdrawal of a Member State was inserted, no one really thought that this provision would ever be applied and even less that it would be so soon".

${ }^{8}$ Para János Martonyi, o ponto de interrogação não se refere ao fato de o Brexit acontecer, e sim a respeito de quando, como e, em primeiro lugar, qual será o novo relacionamento entre o Reino Unido e a EU, questões que são completamente incertas e imprevisíveis. Em suas palavras, "essa imprevisibilidade que levanta não uma, mas uma longa lista de perguntas". Tradução livre de: "To dispel any misunderstandings, the question mark does not refer to the fact that Brexit will happen. It will. But when, how and, first and foremost, what will be the new relationship between the UK and EU is now completely uncertain and unforeseeable. It is this unpredictability that raises not one, but a long list of questions". MARTONYI, János. Brexit. Brexit? ELTE Law Journal. n. 1. 2016. p. 19. 
Ao realizar uma análise crítica sobre a posição da União Europeia no sistema internacional, é preciso considerar algumas premissas. É necessário ter em mente que "o contexto europeu de cooperação em política externa também é moldado pelo acquiscommunautaire e pelo acquispolitique", de modo que "não importa o que o futuro reserva para a capacidade da UE de atuar internacionalmente, os membros estão vinculados a um repertório de posições fixas de política externa” (GINSBERG, 1999, p. 436-437).

Não há dúvidas de que a União Europeia é, atualmente, um importante ator do sistema internacional. Ainda que o bloco econômico esteja atrelado aos interesses dos seus EstadosMembros, percebe-se certa autonomia e capacidade de negociação que diferem das posturas adotadas por um ou outro Estado particularmente. No entanto, não há consenso sobre a sua definição como um ator "independente" do sistema internacional.

A saída do Reino Unido altera os prognósticos do bloco regional e testa, como nunca, a capacidade de negociação da União Europeia. A postura a ser adotada nesse período de transição influenciará na resposta da pergunta feita neste artigo: é possível pensar na União Europeia como um ator internacional, ainda que formado por uma constelação de Estados?

\section{REFERÊNCIAS}

BORRAS, Alegría. La Comunidad Europea como miembro de la Conferencia de la Haya de Derecho Internacional Privado. Anuario Español de Derecho Internacional Privado, Madrid, v. 6, p. 1179-1189, 2006.

BOSILCA, Ruxandra Laura. The European Union - a Sui Generis International Diplomatic Actor: Challenges Posed to the International Diplomatic Law. Romanian Journal of European Affairs, v. 14, n. 1, p. 22-33, 2014.

BRU, Carlos Maria. La Ciudadanía Europea. Madrid: Editorial Sistema, 1994.

DEUTSCH, Karl. Análise das relações internacionais. Brasília: Universidade de Brasília, 1982. p 268.

DIZ, Jamile Bergamaschine Mata; JALES, Rodrigo Tadeu Guimarães. Brexit: Os impactos causados na livre circulação de pessoas pela saída do Reino Unido da União Europeia. In: MOURA, Aline Beltrame de (Org.). O Direito Internacional Privado Europeu: entre a harmonização e a fragmentação. Florianópolis: Emais, 2019. p. 277-306.

GEHRING, Thomas; OBERTHUR, Sebastian; MUHLECK, Marc. European Union Actorness in International Institutions: Why the EU Is Recognized as an Actor in Some International Institutions, but Not in Others. Journal of Common Market Studies. v. 51, n. 5, p. 849-865, 2013. 
GINSBERG, Roy H. Conceptualizing the European Union as an International Actor: Narrowing the Theoretical Capability-Expectations Gap. Journal of Common Market Studies. v. 37. n. 3. 1999. p. 429-454.

HAAS, Ernst Bernard. Beyond the Nation State. Stanford: Stanford University Press, 1964.

JAEGER JUNIOR, Augusto; HERZOG, Benjamin. O Tratado que Estabelece uma Constituição para a Europa. Direito e Justiça: reflexões sociojurídicas, Santo Ângelo, a. 7, v. 10, p. 93-120, 2007.

JAEGER JUNIOR, Augusto. Mercados Comum e Interno e Liberdades Econômicas Fundamentais. Curitiba: Juruá Editora, 2010.

KERTÉSZ, Ágnes. Brexit's Legal Framework. ELTE Law Journal, Budapest, n. 1, p. 93$102,2016$.

MARTONYI, János. Brexit. Brexit? ELTE Law Journal., Budapest, n. 1. p. 19-37, 2016.

MICHAELS, Ralf. The New European Choice-of-Law Revolution. Tulane Law Review, New Orleans: Tulane University, vol. 82, n. 5, p. 1607-1644, maio 2008.

MOLINA DEL POZO, Carlos Francisco. Tratado de Derecho de la Unión Europea. Volumen I. Curitiba: Juruá Editora, 2015.

NYE, Joseph S. Compreender os conflitos internacionais: uma introdução à teoria e à história. Lisboa: Gradiva, 2002.

OLIVEIRA, Odete Maria de. União Europeia - Processos de Integração e Mutação. Curitiba: Juruá Editora, 2002.

OLIVEIRA, Odete Maria de. Velhos e novos regionalismos: uma explosão de acordos regionais e bilaterais no mundo. Ijuí: Unijuí, 2009.

SMITH, Karen E. European Union: A Distinctive Actor in International Relations. Brown Journal of World Affairs, v. 9, n. 2, p. 103-114, 2003.

WAIBEL, Michael. Brexit and Acquired Rights. AJIL Unbound, v. 111, p. 440-444, 2018. 